\title{
Evaluation of mould growth risks due to air leakage through air cavity of the building walls
}

\author{
Xinyuan Dang ${ }^{1}$, Shuichi Hokoi ${ }^{1, *}$, Yonghui $\mathrm{Li}^{1}$, Changchang Xia ${ }^{1}$, and Ma $\mathrm{Yan}^{1}$ \\ ${ }^{1}$ School of Architecture, Southeast University, 210000 Nanjing, China
}

\begin{abstract}
Mould growth causes damage and poses high risk to a large number of existing buildings and their users. Air leakage through air cavity of the building walls, such as gaps between walls and some pipes penetrating the walls, produces obvious hygrothermal exchange, altering the temperature and humidity distribution of the walls. It would promote condensation and mould growth. Air cavity are common on the walls of existing buildings. In order to make a quantitative analysis on the mould growth risks due to air leakage through air cavity, an office room in an existing building in Nanjing, China was selected and hygrothermometers were arranged indoor and outdoor for monitoring. The measured results showed the room was in high temperature and relative humidity from June to early September. Two-dimensional hygrothermal-simulation was made to investigate the hygrothermal conditions of the walls with air cavity, using the measured data as boundary conditions and validation for the numerical simulation. Mould growth risks under these situations were estimated.
\end{abstract}

\section{Introduction}

Dispersion of fungi spores and development of its colony lead to human health risks and degradation of buildings. Sick building syndrome (SBS) was defined as certain medical symptoms experienced by occupants in specific indoor environments, including headache, fatigue and irritation in upper respiratory tract [1]. Inhaled spores can trigger asthma, rhinitis or bronchitis symptoms [2]. The occurrence of mould growth is mainly caused by favorable hygrothermal environment: high temperature, high relative humidity $(\mathrm{RH})$ and condensation.

Currently advanced mould prediction models deal with the main influencing factors for mould growth: the surface temperature and relative humidity. Vereecken et al. [3] reviewed the models for mould growth and environmental risk prediction (isopleth systems, biohygrothermal model, ESP-r mould prediction model, empirical VTT model). Hukka et al. [4] proposed a quantitative relationship between mould growth initiation conditions, maximum growth, and growth rate. Klaus Sedlbauer [5] developed WUFI-bio software to assess mould risk by temperature, humidity and base medium in cases of transient conditions.

\footnotetext{
* Corresponding author: hokoi@seu.edu.cn
} 
Air leakage through air cavity of the building walls, such as gaps between walls and some pipes penetrating the walls, produces severe hygrothermal exchange, altering the temperature and humidity distribution of the wall. It may promote condensation and mould growth in hot and humid climates. However, there is not sufficiently thorough quantitative research for mould growth risks due to air leakage through air cavity of walls (Fig.1).
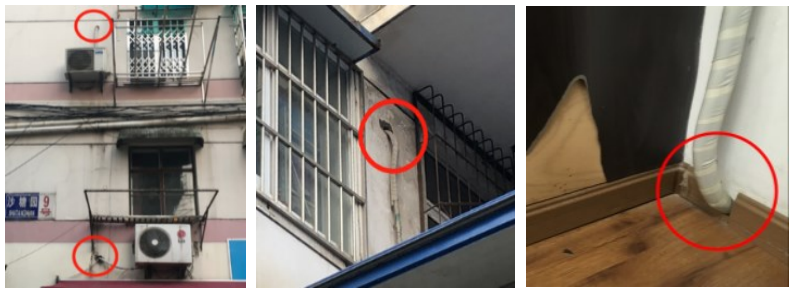

Fig. 1. Air cavities due to air conditioners of the buildings in Nanjing

High relative humidity and proper temperature conditions promote mould growth on the surface of and inside the building walls made of porous materials. In Nanjing, buildings chronically suffer from high humidity due to long rainy season especially sticky summer, and cooling by air-conditioners (hereafter 'AC') along with large heat capacity of building structure may lead to condensation. Smell of mould is frequently felt inside buildings.

To understand such situation, a monitoring has been carried out to investigate the indoor environment, and numerical simulation considering hygrothermal transfer was conducted to evaluate the mould growth risks due to air leakage through air cavity of the building walls.

\section{Survey on Indoor and Outdoor Hygrothermal Conditions}

\subsection{Outline of monitoring}

The monitored building is 'Zhongdayuan Building' of Southeast University located in Nanjing, China (Fig. 2 a) \& b)). It was constructed in the 1920s and was included in the list of the first '20th Century Architectural Heritage of China' in 2016. This three-storey building with south-north orientations is still used as an office building and for teaching. Shrubs surround the building and tall Platanus shade it from the sun during hot seasons.
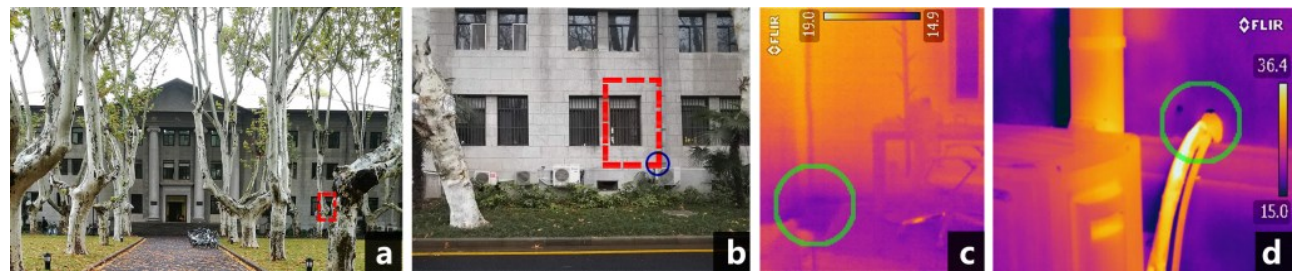

Fig. 2. Zhongdayuan Building: a) \& b) facade of the building and monitored room (in red dashed line) with air cavities (in blue circle), c) \& d) infrared thermography of the air cavity area (in green circle) viewed from inside and outside

The monitored room is on the ground floor, with a window facing south to the outdoor, and connected to the indoor-corridor on the north. It had been used as an office for years and severe mould smell was felt. The measurement started from June 2018. The door and window have been closed except for limited cases when researchers entered the room.

According to the infrared thermography data in March (Fig. 2 c) \& d)), the air cavity area was relatively colder than the adjacent areas, which might result from the air leakage through air cavity and severe regional hygrothermal exchange. In cooling seasons, hot and 
humid outdoor air would be cooled down when passing through the cold air cavity, leading to the condensation and mould growth. In order to eliminate the thermal influence of AC and compare with a situation without AC operation, the room has not been air-conditioned.

About 10 hygrothermometers were arranged in the monitored room and corridor in June, 2018. Figure 3 shows their position. Currently, 9 hygrothermomters are used, 3 in the monitored room (\#60: door, \#67: corner, \#68: windowsill), 1 in the corridor (\#58: corner), 1 outdoor (\#662: outdoor) and 4 in the neighbouring rooms (\#573: 1F, \#593: B1, \#612: GL, \#632: GR). They recorded the air temperature and relative humidity every 30 minutes.

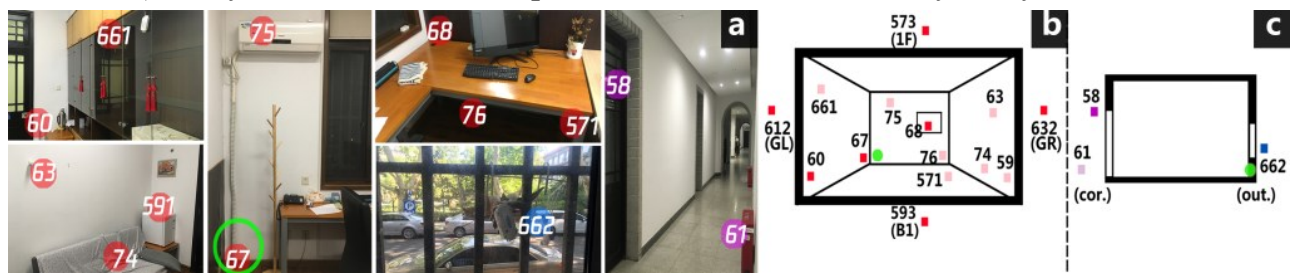

Fig. 3. Position of hygrothermometers: a) pictures of the hygrothermometers (the air cavity of AC pipe: in green circle), b) perspective from the door into the monitored room, c) section of the monitored room (the air cavity of AC pipe: in green circle)

\subsection{Measured results}

Figure 4 shows the average temperature of 3 indoor sensors (\#60: door, \#67: corner, \#68: windowsill) with the outdoor and corner temperatures from June, 2018 to January, 2019.

Even the outdoor temperature shares the similar annual trend with the average indoor temperature, it showed larger diurnal variations $\left(4-10^{\circ} \mathrm{C}\right)$ and stayed approximately $5^{\circ} \mathrm{C}$ higher in summer. The average indoor temperature fluctuated from $5^{\circ} \mathrm{C}$ to $31^{\circ} \mathrm{C}$, higher than the corner temperature by $0.5^{\circ} \mathrm{C}-1^{\circ} \mathrm{C}$. As the door and window were closed, the air cavity of the AC pipe might be the main route for air flow under the indoor and outdoor temperature and pressure differences, along with the air leakage through the window and door.

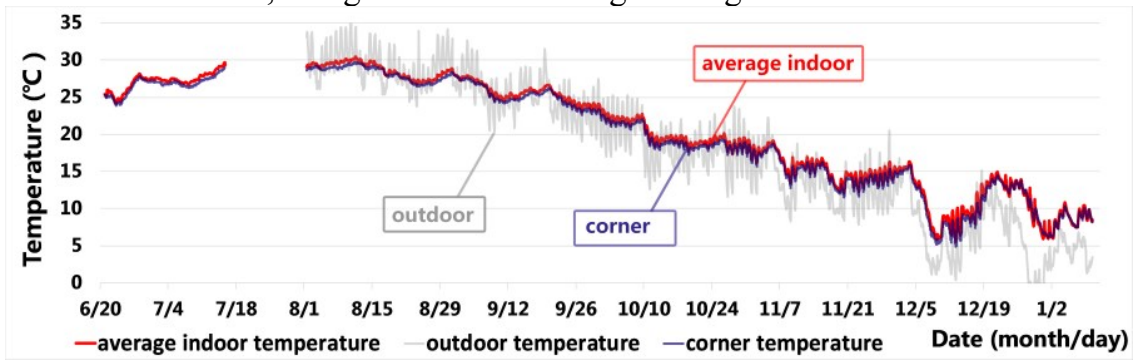

Fig. 4. Average indoor, outdoor and corner temperatures

As shown in Fig. 5 a), the outdoor RH during night almost remained over $90 \%$ and it always stayed higher than the indoor RH. The average indoor RH also maintained high level (70\%-90\%) from July to September, slightly lower than the corner RH. 


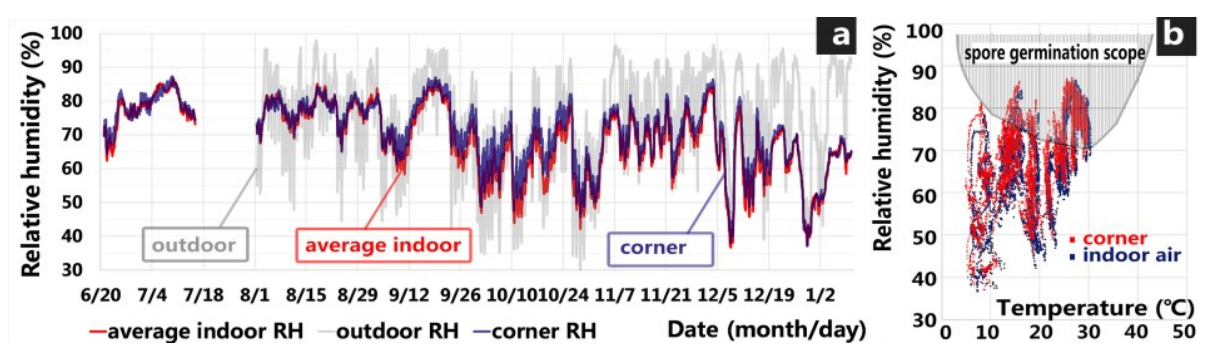

Fig. 5. a) Average indoor, outdoor and corner RH, b) mould growth risks of corner and indoor air

Figure $5 \mathrm{~b}$ ) shows the mould growth risk based on the measured temperature and RH of the corner and average indoor value, according to Klaus Sedlbauer's fungi spores' germination scope evaluation [5]. A considerable proportion of the values fall in the risky area and risk at corner is marginally higher than that of the average during hot seasons.

\section{Hygrothermal Analysis of Room and Wall Constructions}

\subsection{Hygrothermal model for heat and moisture transfer}

In this research, Matsumoto's hygrothermal transient and simultaneous transfer equations (Equations (1)-(5)) are adopted [6-7].

The migration of heat and moisture in porous material, brick in this paper, is a thermophysical phenomenon in which the water changes phases, producing latent heat, accompanied by changes in water content. In this paper, water chemical potential (Gibb's free energy) is used as the moisture potential on the basis of nonequilibrium thermodynamics:

$$
\mu=R_{V} T \ln (R H)
$$

where $\mu$ is water chemical potential, $T$ and $R H$ are absolute temperature and relative humidity; $R_{v}$ is gas constant of water vapor $\left(R_{v}=R / M_{v}\right), R$ is general gas constant and $M_{v}$ is water vapor molecular weight.

Basic equations for heat and moisture balance are given by Equations (2) and (3):

$$
\begin{gathered}
c \rho \frac{\partial T}{\partial t}=-\nabla \cdot q_{s}+r \nabla \cdot J_{1 w} \\
\rho_{\omega} \frac{\partial \psi}{\partial \mu} \frac{\partial \mu}{\partial t}=-\nabla \cdot\left(J_{1 w}+J_{2 w}\right)
\end{gathered}
$$

where, $c \rho$ is specific heat of material, $q_{s}$ is heat flux, $r$ is latent heat of phase change from gas to liquid phase, $\rho_{\omega}$ is density of water, $\psi$ is volumetric water content, and $J_{1 w}$ and $J_{2 w}$ are water flux in gas and liquid phases respectively:

$$
\begin{gathered}
J_{1 w}=-\lambda_{\mu g}^{\prime}\left(\nabla \mu-n_{x} g\right)-\lambda_{T g}^{\prime} \nabla T \\
J_{2 w}=-\lambda_{\mu l}^{\prime}\left(\nabla \mu-n_{x} g\right)-\lambda_{T l}^{\prime} \nabla T
\end{gathered}
$$

Two-dimensional hygrothermal model is used in the simulation and heat and moisture balance equations inside the material are given by Equation (6) and (7):

$$
\begin{gathered}
c \rho \frac{\partial T}{\partial t}=\frac{\partial}{\partial x}\left[\left(\lambda+r \lambda_{T g}^{\prime}\right) \frac{\partial T}{\partial x}+r \lambda_{\mu g}^{\prime}\left(\frac{\partial \mu}{\partial x}-n_{x} g\right)\right]+\frac{\partial}{\partial y}\left[\left(\lambda+r \lambda_{T g}^{\prime}\right) \frac{\partial T}{\partial y}+r \lambda_{\mu g}^{\prime}\left(\frac{\partial \mu}{\partial y}-n_{y} g\right)\right] \\
\rho_{\omega} \frac{\partial \psi}{\partial \mu} \frac{\partial \mu}{\partial t}=\frac{\partial}{\partial x}\left[\lambda_{\mu}^{\prime}\left(\frac{\partial \mu}{\partial x}-n_{x} g\right)+\lambda_{T}^{\prime} \frac{\partial T}{\partial x}\right]+\frac{\partial}{\partial y}\left[\lambda_{\mu}^{\prime}\left(\frac{\partial \mu}{\partial y}-n_{y} g\right)+\lambda_{T}^{\prime} \frac{\partial T}{\partial y}\right]
\end{gathered}
$$

The heat and moisture balance of the air in the air cavity were dealt with by onedimensional air flow with a velocity $v[\mathrm{~m} / \mathrm{s}]$. 


\subsection{Simulated room and wall structure}

Simplified from the main section of the monitored room, a two-dimensional hygrothermal simulated model is made, as shown in Fig. 6 a).

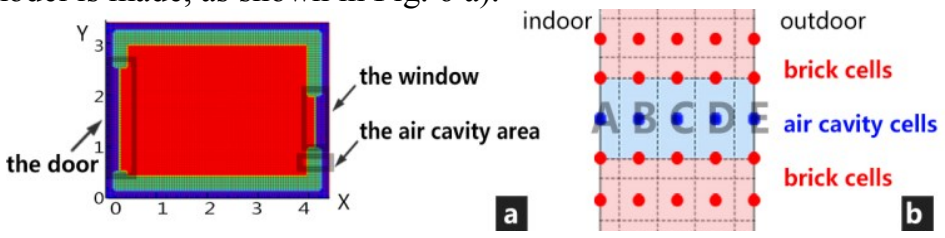

Fig. 6. a) Mesh of the simulated room, b) mesh of the air cavity area (air cavity cells 'A'-'E' in blue)

The size of the simulated room is $4 \mathrm{~m}$ (deep) $* 3 \mathrm{~m}$ (high) and thickness of floors and walls is $200 \mathrm{~mm}$. The mesh numbers are 80 by 60 . A door $(\mathrm{x}=0.2 \mathrm{~m}-0.4 \mathrm{~m}, \mathrm{y}=0.5 \mathrm{~m}-2.5 \mathrm{~m})$, a window $(\mathrm{x}=4.0 \mathrm{~m}-4.2 \mathrm{~m}, \mathrm{y}=1.0 \mathrm{~m}-2.0 \mathrm{~m})$ and air cavity area (located at $\mathrm{x}=4.0 \mathrm{~m}-4.2 \mathrm{~m}$, $\mathrm{y}=0.45 \mathrm{~m}-0.55 \mathrm{~m})$ are set. All the walls and floors are made of the same solid material, i.e. brick, and typical brick characteristics in South China are used as the material properties [8] in the simulation.

The measured temperature and relative humidity in the neighboring rooms (\#58: corridor, \#662: outdoor, \#573: 1F, \#593: B1) were used as the boundary conditions of the simulations while the measured results from $\# 60$ (door) were used for validation purpose.

\section{Calculated Results}

\subsection{Validation}

As shown in Fig. 7, a good agreement was obtained between the measured and calculated indoor air temperatures and absolute humidity. Although the calculated indoor temperature lagged slightly behind the measured temperature, it shows clear dinual variations. The calculated absolute humidity also agrees fairly well with measured results on the average.

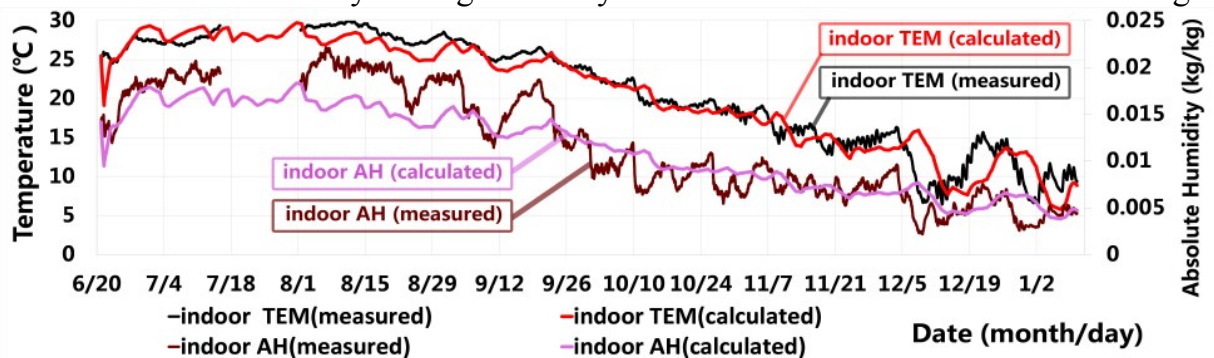

Fig. 7. Comparison of the measured and calculated temperatures and absolute humidity

\subsection{Comparison among the cells in the air cavity}

The air cavity area consists of 5 cells, named by code 'A' - 'E' from the indoor side to the outdoor side (Fig. 6 b)). In the following, cell 'B' (the second cell from the indoor boundary) and ' $E$ ' (outdoor boundary cell) are used for estimating the mould growth risks.

As shown in Figure 8, the temperatures of cell ' $B$ ' and ' $E$ ' change in a similar manner and almost in the same range of the corner temperature, while the annual variations of cell ' $E$ ' temperature are more closely related to the outdoor values. In Figure 9 a), the relative humidity of ' $E$ ' shows the same tendency with that of outdoor, staying at high level $(70 \%$ $90 \%$ ) for a long period, while cell 'B' remains at relatively lower RH level. 


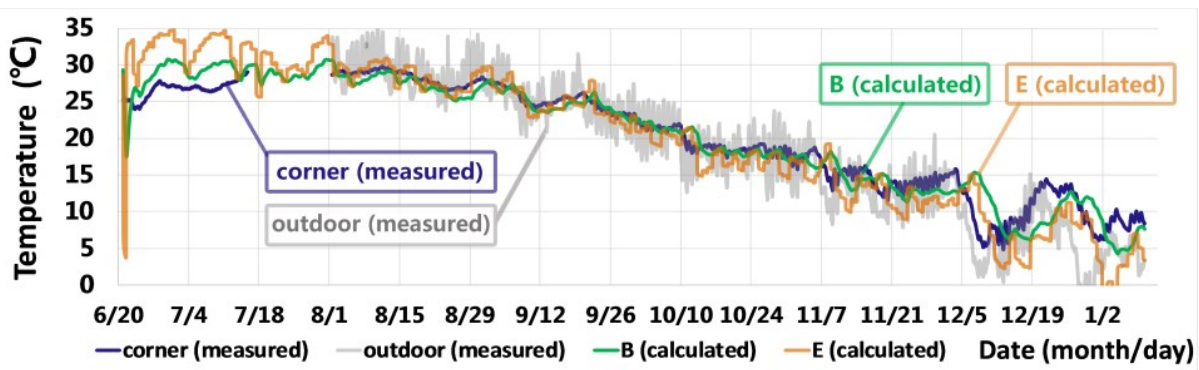

Fig. 8. Calculated temperatures of cell ' $B$ ' and ' $E$ ' with measured corner and outdoor temperatures

In Figure 9 b), mould growth risks have been assessed based on Klaus Sedlbauer's fungi spores' germination scope evaluation. Compared with that of average indoor air (as shown in Fig. 5 b)), there are more points of air cavity cells, especially for cell 'E', lying in the risky zone. It indicates that the air cavity cells near the outer boundary seem to have a higher risk to generate fungi spores.
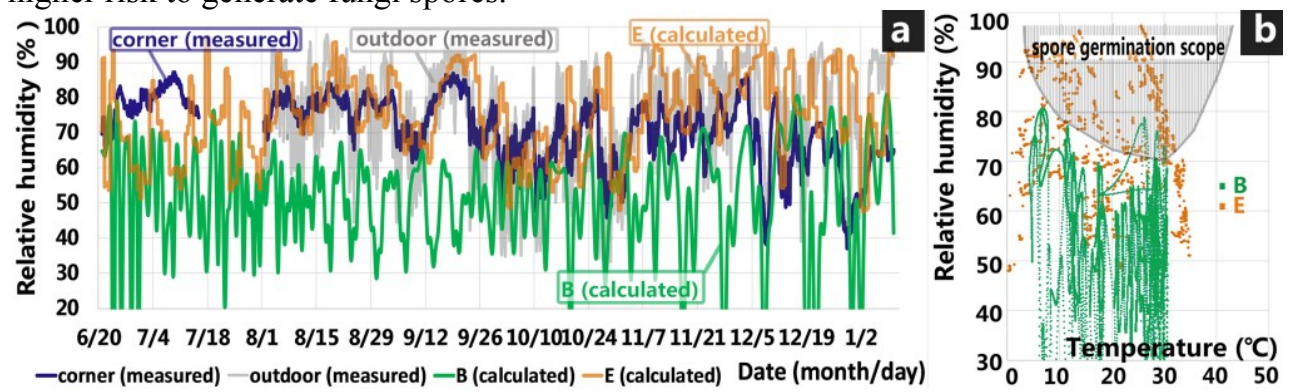

Fig. 9. a) Calculated RH of cell 'B' and 'E' with measured corner and outdoor RH b) mould growth risks of cell ' $\mathrm{B}$ ' and ' $\mathrm{E}$ '

\section{Conclusion}

In this study, temperature and RH in an existing office building in Nanjing City have been measured. The measured results showed the building walls have been exposed to high relative humidity for a long period during hot seasons, favorable conditions for mould growth.

Two-dimensional hygrothermal simulation was conducted to examine the hygrothermal conditions of the walls with air cavity penetrating the walls for AC drainage pipe, using the measured data as boundary conditions and validation for the numerical simulation. The air cavity may cause condensation and mould growth. Exposed to the outdoor damp air, the outer parts of air cavity are more likely to be favorable for mould to produce fungi spores.

In this paper, the air conditioner was not operated in order to examine the influence of air leakage and heat capacity of brick wall, and to make clear AC drainage pipe's cooling impact on the outdoor humid air through the air cavity in summer. Since the measurements are continuously conducted, the hygrothermal data during AC operation will be obtained in the near future. This paper is only a beginning, and long-term and detailed measurements along with the validation of the proposed simulation model remain to be done in further research.

This work was supported by NSFC (No. 51878140) and Natural Science Foundation of Jiangsu Province (No. BK20161424). 


\section{References}

1. WHO, Indoor Air Pollutants: Exposure and Health Effects, (Copenhagen, 1983)

2. C. Brian, B. Nancy C, Fungal Biol. Rev. 24, 106, (2010)

3. E. Vereecken, S. Roels, Build. Environ. 51, 296, (2012)

4. A. Hukka, H. A. Viitanen, J. Wood Sci. 33, 475, (1999)

5. K. Sedlbauer, Prediction of mould fungus formation on the surface of and inside building components, (Dissertation, University Stuttgart 2001)

6. M. Matsumoto, New Series of Architecture, (Moisture, Shokokusha Co., Ltd., 1984)

7. M. Matsumoto, S. Hokoi, E. Ka, ASHRAE Trans. 103, 573, (1997)

8. H. Xie, Analysis of performance degradation of the Chinese traditional blue bricks based on the theory of heat and moisture transfer, (Thesis, Southeast University 2013) 